\title{
Saúde e doença no Alto Amazonas
}

\author{
AXEL KROEGER \\ Freiburg Universität, Baden Wuertemberg, Alemanha \\ kroegera43@gmail.com \\ FRANÇOISE BARBIRA-FREEDMAN \\ University of Cambridge, Cambridge, Cambridgeshire, Reino Unido \\ fb205@cam.ac.uk \\ Tradução: Aline REgitANO (D) e ANAI VERA BRITOS \\ Universidade de São Paulo, São Paulo, São Paulo, Brasil
}

DOI 10.11606/issn.2316-9133.v29i2pe180512

\section{A percepção de saúde e medidas para mantê-la}

Para os indígenas do Alto Amazonas - característica também compartilhada por outros grupos - as oscilações diárias nas condições físicas dos membros de suas aldeias são objeto de considerável atenção. Em primeiro lugar, o ritual de conversa antes do amanhecer, formalizado tanto nas famílias Quechua Lamas (previamente conhecidas como Lamistas) quanto nas Shuar, permite que os indivíduos reúnam informações sobre o estado de saúde dos moradores. Os planos cotidianos são, então, modificados se alguém se levantar se sentindo mal. $\mathrm{O}$ fato de ter tido um pesadelo poderia ser interpretado como algo nefasto, e essa noção de bem-estar é parte integrante de uma percepção da saúde como um estado que abrange mais do que a ausência de doença. A noção de saúde está associada a estar em boa forma, a ter força física e à higiene, incluindo, além disso, resistência à feitiçaria ou ataques de espíritos. A fraqueza e o estado de "sujeira" estão associados, portanto, à vulnerabilidade a tais ataques.

Tanto entre os Shuar, quanto entre os Quechua Lamas, a saúde dos homens adultos recebe abertamente mais importância do que a de outros membros da família. De madrugada, as mulheres Quechua Lamas se informam sobre as condições de saúde de seus

\footnotetext{
${ }^{1}$ Esta é uma tradução do capítulo 5 do livro "La Lucha por la salud indígena en el Alto Amazonas y en los andes (1992)”, que foi ampliada pelos autores e apresenta notas inéditas (sinalizadas com um asterisco).
} 
pais, maridos ou sogros, enquanto levam para eles vasilhas com água para lavar a boca². No entanto, os homens não retribuem da mesma forma, e a condição da mulher só terá importância quando o seu estado de saúde for considerado crítico. Todavia, nas casas dos colonos (migrantes andinos que se instalaram na Amazônia), seus membros não realizam essa interação ritual diária, e todos se dirigem diretamente às diferentes atividades cotidianas assim que acordam. Apenas aqueles indivíduos que não estão bem ou são mais propensos às doenças, são perguntados sobre sua condição de saúde.

Para os povos indígenas de áreas remotas do Alto Amazonas, e especialmente para os homens, a caça ${ }^{3 *}$ continua sendo a principal atividade a que se dedicam. A caça requer boas condições físicas daquele que a pratica, o que inclui não apenas a capacidade de enfrentar as adversidades físicas, mas também a capacidade de lidar com os riscos de encontrar os espíritos das matas, o que pode ser um encontro fatal, caso o caçador não esteja em bom estado. Um encontro desse tipo poderia produzir um choque permanente e acabar arruinando sua sorte pelo resto de sua vida. Por isso, homens que não se sentem física e mentalmente bem, evitam caçar ou fazer caminhadas se puderem, sem incorrer em grave preconceito social, ou seja, quando sua presença não é exigida por parentes próximos, ao planejarem, por exemplo, uma caça em equipe.

Por isso, os homens que não estão em boas condições físicas não realizam atividades externas e ficam em casa por certo período. Isto pode variar de um dia a uma semana, quando se dedicam a tarefas que podem parecer mais "fáceis", como carpintaria, confecção de cestarias, e tecelagem de algodão. Ou, eles podem apenas descansar, deitados, em redes, por um período de um a três dias, diferente de como costumam fazer quando usam plataformas ${ }^{4}$ de dormir para passar a noite.

\footnotetext{
${ }^{2}$ Ao acordarem antes do amanhecer, os indígenas Shuar/Achuar bebem chá de Guayusa, que logo vomitam. Isso não é feito como um tratamento para uma doença específica, mas como uma prática regular. Quando disponíveis, bebem masato (cerveja de milho) e "chicha" (cerveja de mandioca), e iniciam a conversa ritual, que varia em duração e intensidade de acordo com os assuntos a serem discutidos. Os indígenas Quechua Lamas primeiro lavam a boca com água e depois bebem chá de ervas ou café. Então, bebem a chicha ou masato, se tiver. Só depois, todas as decisões importantes sobre os membros da família são feitas. Os xamãs frequentemente examinam os pacientes e realizam curas naquele momento.

${ }^{3}$ A caça era a fonte principal de proteína animal dos Quechua Lamas na década de 1970 (e ainda é, mas agora mais escassa). Eles também consumiam muito peixe salgado (faziam pescarias sazonais para pegar Bocachico Prochilodus Magdalenae, agora ameaçado com extinção - e Paiche - Arapaima gigas, agora criados em pescarias no Baixo Amazonas, como suas duas espécies favoritas). Galinhas, e mais tarde porcos - híbridos de porcos domésticos e selvagens - eram criados, mais para venda do que para comer. A proteína diária era obtida de áreas de floresta secundária na forma de caracóis, pequenos peixes, lagostins e alguns insetos. As nozes e as palmeiras, que tinham um teor proteico significativo, desempenhavam um papel importante na dieta dos indígenas da época, e ainda o fazem, principalmente a Chonta (Bactris gasipaes, pupunha).*

${ }^{4}$ Essas são plataformas de madeira erguidas do chão, feitas com pranchas, ou pequenos troncos de árvores amarrados. Pais e filhos dormem juntos neles, às vezes com outros parentes. O fogo é mantido próximo aos leitos da plataforma em locais que são frios à noite, geralmente acima de $400 \mathrm{~m}$. Às vezes, há plataformas separadas para meninos e meninas adolescentes nas casas maiores. Quando as pessoas estão doentes, é comum
} 
Alguém que deseja melhorar seu estado físico e mental deve seguir uma dieta especial, evitando sal, pimenta, gordura e doces. Outros bebem preparados à base de ervas, feitos por eles mesmos, ou por um parente mais habilidoso, sendo às vezes preparado por um curandeiro. Os caçadores Quechua Lamas se tornaram famosos ao longo do Alto Amazonas pelo preparo de remédios fortificantes, geralmente conhecidos como "purgas", cujo uso é ainda muito difundido. As purificações causam vômito e/ou diarreia, pois se acredita que isso depura o corpo. Esses remédios são sempre preparados por eles mesmos ou por outros homens, mas nunca com a ajuda de mulheres. As "purgas" são consideradas promotoras de força física, virilidade e, sobretudo, de boa sorte do caçador em sua empreitada.

Antes de ir à caça, o caçador e seu cão devem seguir prescrições, tanto alimentares como de outros tipos. Como já dissemos, eles devem se abster de comer sal e de ter relações sexuais. Eles devem descansar "brincando de preguiça". O homem se deita e o cachorro é amarrado. É assim que, na noite da lua crescente, ambos, homem e cachorro, bebem a purga, que está associada a algum propósito específico. Por exemplo, se diz que a "Pikuru Papa" e a "Congona" ajudam no sucesso da caça de tatu. A purga também inclui um conjunto diferente de prescrições e proibições, consideradas segundo a fase diferente da lua. Além disso, é utilizada fumaça de tabaco, através do sopro: o caçador sopra a si mesmo e aos seus cachorros. $\mathrm{Ou}$, esfrega folhas de manjericão no próprio corpo e também em seus cachorros, processo denominado de "cura" (Quechua = ampichiy), sendo também feito antes da atividade de caça.

Contudo, em toda a região amazônica, os não-indígenas consideram que os indígenas são preguiçosos. Essa percepção é baseada nos longos períodos que os indígenas passam descansando, o que, na realidade, resulta da prática indígena de alternar períodos de atividades extenuantes com os de descanso; o calendário anual também permite fases em que esses períodos de descanso são a norma, especialmente durante a estação das chuvas e excursões de caça. Ao longo do ano, também existem formas socialmente aceitas pelas quais os homens são liberados de realizar suas tarefas diárias. Por exemplo, quando uma viagem de caça é realizada com apenas uma de suas esposas, o homem Shuar é dispensado de suas obrigações para com o resto de sua família polígama. Por outro lado, as famílias nucleares Quechua Lamas apreciam muito da liberdade e do descanso da vida que áreas mais afastadas

ficarem confinadas a redes, em vez de deitadas nas camas da plataforma. Bebês e crianças pequenas são colocados para dormir em pequenas redes de tecido. Portanto, para os adultos doentes, as redes estão associadas ao conforto e ao descanso diurno. As pessoas fazem sestas diurnas em redes, nunca em camas de plataforma.*

\footnotetext{
${ }^{5}$ Solanum crinitum Lam. A fruta é consumida pela cutia e é chamada, no Alto-Amazonas, de Pikuru ou Majas. Três alcalóides, tri-glicosil-esteróides, solamargina, epi-solamargina e solasodina foram isolados do extrato metanólico dos frutos verdes.*

${ }^{6}$ Peperomia inaequalis folia. Suas folhas são usadas para tratar otites, dores de cabeça e também dores pós-parto. A planta é usada pelos xamãs para limpar o corpo das pacientes.*
} 
oferecem, longe das pressões que recebem tanto dos parentes da aldeia quanto dos colonos mestiços, que muitas vezes exigem o pagamento de dívidas com trabalho. Finalmente, é necessário dizer que os períodos de descanso em casa ou em áreas afastadas no mato são fases geralmente associadas a um pequeno consumo de alimentos.

Como se dedicam ao cuidado da casa e à criação dos filhos, as mulheres têm menos oportunidades de descanso, mesmo se estiverem cansadas, ou não se sentirem bem. $\mathrm{O}$ descanso do homem depende de encontrar uma mulher que assuma as tarefas domésticas, o que é mais fácil em famílias extensas, como entre os Quechua Lamas e os Shuar. Se seus maridos mudarem para novos espaços na mata como pioneiros, onde não há parentes do sexo feminino, as jovens mulheres Quechua Lamas devem suportar grandes adversidades. Ao contrário dos homens, as mulheres não podem desfrutar de períodos de preguiça aceitos socialmente, exceto no período pós-parto. Algumas atividades, como fiar, mastigar mandioca fervida para fazer "masato" (chicha), purgar outras pessoas e tomar banho, são estratégias frequentemente utilizadas pelas mulheres para relaxar e se descontrair de outras tarefas. Normalmente, uma mulher não pode nem mesmo deitar para descansar, senão poderia ser considerada como "doente". Nesse sentido, deve-se acrescentar que a ajuda mútua entre parentes obedece estritas regras de reciprocidade. Por fim, as mulheres não tomam os mesmos remédios fortificantes que os homens, embora existam remédios à base de ervas que elas podem preparar. Os xamãs também podem, ocasionalmente, preparar remédios fortificantes para elas ${ }^{7}$.

Da mesma forma, pouca importância é dada à saúde das crianças entre os indígenas, exceto quando houver excesso de parasitas intestinais, que é um tema de interesse geral. As crianças, tanto filhos e filhas de indígenas como dos colonos, recebem regularmente vermífugos. Os colonos costumam criticar o que consideram uma falta de interesse dos pais indígenas por seus filhos com mais de três anos de idade. Os professores frequentemente falam de seus esforços para "educar" os pais indígenas na cura das feridas de seus filhos, e da falta de cuidado deles quando não estão bem, e assim por diante. Nossas observações confirmam que, de fato, os pais Quechua Lamas provavelmente não fazem nada para aliviar a dor de seus filhos causada, por exemplo, por feridas infectadas. Eles podem até se recusar a transportar crianças que sofreram uma fratura para o posto de saúde mais próximo, embora não se oponham a usar os postos de saúde, quando se trata de suas próprias doenças. Mas, por outro lado, tanto os pais Quechua Lamas como os Shuar/Achuar, podem abandonar suas casas ou sua região para passar várias semanas na casa de um xamã, a fim de obter a cura de um filho doente. Inclusive, podem viajar para hospitais distantes em busca de cuidados para seus filhos. Apesar das variações individuais, fica claro então que a saúde dos homens adultos é a mais valorizada, em segundo lugar a saúde das mulheres jovens e dos adolescentes e, por último, a das crianças pequenas e dos bebês.

\footnotetext{
${ }^{7}$ Um número muito pequeno de mulheres são identificadas como xamãs.
} 
Homens e mulheres revelam que comem e bebem bem e têm acesso a uma grande variedade de alimentos, o que é considerado um sinal de boa saúde. Frequentemente, seguir uma dieta envolve um processo de purificação, enquanto comer muito pouco é um sinal de fraqueza, ou de problemas de saúde. Os homens também enfatizam o consumo de grandes quantidades de masato, chicha de milho e mandioca, como indicador de boa saúde, já que isso faz referência à sua potência sexual. Muitos acreditam que a saúde da mulher adulta se manifesta na ausência de distúrbios ginecológicos, geralmente expressos por dores na região abdominal inferior e sangramento vaginal.

Entre os povos indígenas do Alto Amazonas, a boa saúde também é geralmente expressa em termos de gordura e volume. Meninas e mulheres jovens são admiradas quando sua gordura aparece. Tanto os homens como as mulheres consideram que a doença está associada à perda de peso ou "ressecamento", e se pensa que o feitiço induz particularmente um processo de "ressecamento", rápido ou lento. Entretanto, essa última crença pode ser específica do Alto Amazonas, embora também seja encontrada nos Andes e em outras partes da América Latina. Outra doença aguda é reconhecida especialmente por inchaço, particularmente do abdômen. Isso requer intervenção imediata, especialmente se for considerada causada por um feitiço. "Ele inchou e morreu", é uma frase frequentemente ouvida tanto entre os indígenas quanto entre os colonos das áreas Lamista e Shuar.

\section{O papel da pessoa doente}

Assim como ocorre com outras populações semelhantes, os indígenas do Alto Amazonas não permitem que os indivíduos assumam o papel de doentes, a menos que sejam realmente incapazes de exercer as tarefas exigidas por serem homens ou por serem mulheres. Uma vez aplicada a terapia apropriada, que pode ter envolvido a visita de vários curandeiros, aqueles pacientes que não se recuperam podem ser encorajados a retomar suas tarefas normais com a ajuda de seus parentes. Quer dizer, não há providências para pessoas com doenças crônicas. Espera-se que um homem idoso realize as tarefas normais da mesma forma que um adulto, até o dia em que esteja tão fraco que não seja capaz de colher os produtos de sua própria roça. Quando é provado então que já estão fracos demais para cumprir essa tarefa, são tachados de "velhos" e se tornam dependentes no que se refere às suas necessidades diárias. Nesta fase, todos, incluindo o velho, irão esperar a morte como algo iminente.

Em contraste, a doença aguda produz uma verdadeira crise social. Parentes próximos são mobilizados imediatamente, e os mais distantes são informados, mesmo morando longe. A busca por terapia começa inicialmente fora de casa, primeiro entre parentes e depois fora do grupo de parentesco. $\mathrm{Na}$ ausência de meios materiais, outras pessoas podem emprestar bens ou dinheiro para custear o tratamento. Nesse caso, porém, as percepções de status afetam as atitudes das pessoas em relação à doença aguda, pois, se for necessário dinheiro para transportar o paciente a um hospital distante para tratamento médico, os Quechua Lamas estarão mais dispostos a enfrentar despesas se o doente for homem do que se for mulher. Por exemplo, alguns homens Quechua Lamas afirmaram preferirem alocar recursos 
em dinheiro para o funeral de uma mulher parente distante, em vez de pagar para que ela fosse tratada em um hospital.

\section{Diferenças entre colonos e indígenas quanto aos conceitos e atitudes em relação às doenças}

No que diz respeito a saúde e doença, os colonos não deixarão de querer diferenciar seu estilo de vida e percepções daquelas dos indígenas. Assim que chegaram ao Alto Amazonas, em ondas sucessivas a partir do século XVIII, trouxeram consigo certas atitudes e práticas em relação à conceituação e ao cuidado com a saúde. Por exemplo, as categorias de quente e frio, e os princípios humorais foram transmitidos de geração em geração desde os tempos coloniais. Porém, em tempos mais recentes, os colonos se tornaram especialistas na adoção de línguas ocidentais, explicando as doenças em termos de infecções microbianas e virais. A cirurgia goza de considerável prestígio entre eles, principalmente se realizada em um hospital regional ou na capital.

Ao contrário dos indígenas, que tendem a comentar suas doenças de forma global, exceto em casos de dores agudas e localizadas, os colonos declaram sobre sua saúde referindo-se a partes específicas do corpo ou a enfermidades específicas. O estômago, o fígado e o coração são os órgãos mais mencionados. Pode-se dizer que o reumatismo e a pressão alta e baixa também são comuns. Muitos outros conceitos que expressam uma forma de somatização de distúrbios realmente psicossociais são utilizados, principalmente entre as mulheres colonas, onde "punzadas" (dor aguda e intermitente no estômago, "pulsario" (pulsações no abdômen)), "nervos”, "bilis", são termos comuns. As doenças acima exigem um tipo especial de tratamento, no qual os serviços de curandeiros tradicionais e do pessoal dos serviços de saúde formais são necessários.

No entanto, os colonos geralmente têm atitudes ambíguas em relação às práticas indígenas de saúde e também ao conhecimento subjacente a essas práticas. Apesar de que, enquanto "pessoas brancas", possam tirar melhor proveito da medicina ocidental, geralmente concordam que algumas práticas indígenas específicas, como o uso de plantas, são valiosas. Um exemplo é o da chamada "sangue de dragão" (G. erythrochilus). Atualmente é vendida já cozida nas barracas dos herbários das cidades de Lima e Quito. O remédio pode ser tomado internamente, ou aplicado externamente para permitir a cicatrização.

A contradição é mais comumente expressa em relação às curas e feitiços dos xamãs. Quando discutem sobre tais práticas com um pesquisador, os colonos podem alegar que os curandeiros tradicionais são ignorantes ou prejudiciais e que devem ser denunciados. Mas, uma vez que houver uma atmosfera de confiança mútua, admitirão que eles também recorrem às práticas dos curandeiros, seja para o tratamento de doenças que os médicos não são capazes de curar, seja no caso de doenças atribuídas a feitiços. Em relação às atitudes sobre a feitiçaria, também ocorrem comportamentos variáveis de uma área para outra do 
Alto Amazonas. Alguns colonos no Vale Upano (Equador) nunca reconhecerão, por exemplo, que os xamãs Shuar podem ser eficazes contra eles. Os colonos do Alto Amazonas peruano, por sua vez, tendem a acreditar que todos os povos indígenas são potencialmente feiticeiros. Por isso, embora as percepções e práticas dos colonos sejam distintas de muitas maneiras daquelas indígenas, eles assumem uma série de crenças e práticas indígenas e, em algumas regiões, até integraram a feitiçaria indígena e o xamanismo às suas próprias práticas.

\section{Busca de terapias e medidas preventivas}

A primeira busca por terapia começa quase invariavelmente com os cuidados em casa $^{8}$. Embora a maioria dos nativos acredite nos poderes nefastos dos xamãs malévolos e, atribuem muitas das doenças à feitiçaria, a prevenção da doença e o cuidado de cada caso recebem grande importância. Inicialmente são experimentadas várias formas de autocuidado antes de recorrerem aos xamãs para diagnóstico e tratamento. Sendo assim, todos os indivíduos estão familiarizados com certas formas básicas de atendimento domiciliar e comportamento preventivo. Chefes de família - mesmo aqueles que não são xamãs, que não possuem conhecimentos especializados sobre a saúde dos familiares - vão preparar purgas com casca de árvores e cipós. As mulheres preparam remédios fitoterápicos à base de plantas e realizam o ritual de purificação através do sopro em outros membros da família. Há chefes de família que também desenvolveram habilidades especiais, pelo que ganharam fama, portanto, são consultados, apesar de que nunca tenham se tornado especialistas, xamãs ou curandeiros, e continuem vivendo como caçadores e horticultores.

Como já observamos, o comportamento preventivo é extenso. Entre os indígenas das matas, esses comportamentos preventivos são principalmente de natureza higiênica, ou baseados em noções de cosmologia, e na classificação simbólica de plantas e animais. As regras alimentares também derivam da magia imitativa. Por exemplo, as mulheres grávidas Quechua Lamas não comem a carne dos mamíferos escavadores que ficam em suas tocas, pois consideram que seus bebês podem ter dificuldade para descer pelo canal de parto.

A oposição quente/frio é geralmente generalizada em todo o Alto Amazonas, embora não seja tão prevalente e tenha muito menos significado simbólico do que nos Andes. Considera-se que deve ser evitado qualquer excesso de calor ou frio. No entanto, há divergências consideráveis sobre como classificar doenças e alimentos, em quente ou frio. Na região Quechua Lamas, por exemplo, a noção de "ar" é atribuída ao frio e é considerada uma causa geral de doenças naturais; e o conceito de "ar" refere-se especificamente à exposição do corpo ao ar frio ou à água. A "febre”, por outro lado, é vista como uma causa potencial de infecções no peito, mas não tão arriscada para a saúde quanto o "ar".

\footnotetext{
8 "Assistência domiciliar", terminologia utilizada neste texto, inclui todos os tratamentos oferecidos em casa por familiares, bem como o autocuidado, incluindo o uso de medicamentos obtidos na farmácia ou na loja (do "vendedor de medicamentos"). A atenção domiciliar não é estritamente um tipo de "automedicação", como é considerada no caso no Ocidente, mas sim como uma série de terapias recomendadas informalmente por pessoas ligadas ao paciente por meio da esfera doméstica de atividades.
} 
As crenças existentes sobre as almas dos mortos também são variáveis entre os grupos indígenas. Há um consenso entre colonos e indígenas, de que a proximidade de cadáveres e locais de sepultamento representa um risco para a saúde, e que as almas dos mortos são capazes de transmitir doenças. A morte e os funerais tornaram-se, portanto, fontes de regras preventivas, incluindo profilaxia, purificação e evitar o contato. Por esse motivo, é comum carregarem cânfora nos bolsos ou beber cânfora amassada na água, usar uma cruz ou um amuleto, acender incenso e velas, ou levar um dente de alho na boca, ou algo semelhante. Pode-se observar que essas regras são seguidas de perto, tanto nas aldeias indígenas quanto nas dos colonos.

$\mathrm{Na}$ medida em que os colonos compartilham as crenças e esquemas de classificação dos indígenas, eles também seguem frequentemente as mesmas regras de comportamento preventivo. Na região Quechua Lamas, todos os colonos tomam muito cuidado de não andar em poças de lama, mesmo que calçados, pois se acredita que ali possam contrair doenças do arco-íris. Em relação à higiene e ao senso de prevenção de doenças, os indígenas das matas parecem ainda mais insistentes do que os colonos. Se uma epidemia estourar em uma área, os indígenas se mudarão rapidamente para sítios distantes ou irão visitar parentes distantes. Os colonos, pelo contrário, tendem a ficar no mesmo lugar sem se deslocar. Além disso, na região Quechua Lamas, quando a catapora se espalha para fora das aldeias mestiças, isso é imediatamente interpretado como um sinal de que devem se mudar para uma aldeia mais afastada.

Da mesma forma, povos indígenas e colonos vão utilizar substâncias e objetos profiláticos para se protegerem de doenças e para promover boa saúde e boa sorte. Em todo o Alto Amazonas, os colonos, especialmente as mulheres, usam objetos de culto católicos (crucifixos, ícones). Esses objetos são utilizados ou pendurados em suas casas para se protegerem contra doenças e, mais especificamente, contra feitiços. Algumas plantas aromáticas, como o alecrim e a arruda, que se acredita terem qualidades protetoras, são plantadas ao redor das casas. Um grande número de plantas e substâncias são usadas para proteção, tanto para promover a saúde quanto para a sorte.

Os indígenas também usam animais e itens vegetais específicos, geralmente associados à cosmologia e ao simbolismo, para fins profiláticos. Entre os Quechua Lamas, por exemplo, bebês recebem pulseiras profiláticas com castanhas Shacapa, macho ou fêmea, de acordo com o sexo. Esta castanha também é usada para fazer chocalhos para os xamãs. Os homens também carregam faixas feitas com pele de iguana nos braços. A iguana é relacionada com o espírito da água que preside as práticas xamânicas (Yaku Runa). Por sua vez, as mulheres vestem pulseiras de contas tingidas de índigo e também tingem seus corpos. Acredita-se que as sementes vermelhas e pretas do Wairuru (Batesia floribunda Spruce) oferecem proteção especial contra a bruxaria. As cores vermelha e preta são da bruxaria, enquanto as cores da cura xamanista são vermelho e branco.

\section{A dieta para os doentes e a purificação}


No momento em que os nativos não se sentem bem, o descanso necessário é acompanhado de uma dieta que constitui uma versão menos rígida do que a praticada pelos xamãs durante seu treinamento e que é prescrita aos pacientes gravemente doentes. Em todo o Alto Amazonas, essa dieta será uniforme: proíbe as gorduras, principalmente da carne de porco, ingrediente essencial na culinária mestiça, mas pouco utilizado pelos indígenas. Também é proibido o sal e os temperos, principalmente a pimenta-malagueta, doces e rum. Idealmente, animais de caça assados ou defumados, e peixes magros com banana são os itens consumidos durante as refeições. Na prática atual, entretanto, o indivíduo come apenas banana, ou mandioca, ou faz um jejum integral. Enquanto durar a restrição alimentar, as relações sexuais também são proibidas, recomendando aos pacientes que voltem para casa sem receber visitas. No Alto Amazonas, do atendimento domiciliar à cura xamanista, todos os cuidados de saúde tradicionais incluem essa dieta; mas entre os colonos não é tão rígida.

$\mathrm{O}$ alimento considerado mais adequado para curar um doente é o caldo de galinha. Evita-se enfaticamente a carne e a gordura de porco, assim como o pimentão usado como tempero. Acredita-se que dietas e purgas restabelecem um estado de pureza física, considerada a verdadeira condição sine qua non de uma boa saúde.

Portanto, o princípio encontrado na dieta e nos cuidados domiciliares é o da "purificação". A alimentação é acompanhada por outros remédios típicos conhecidos como purgas, que podem ter uma variedade de efeitos, mas quase sempre induzem a vômito ou diarreia, ou ambos ao mesmo tempo. A ideia em jogo aqui é eliminar as substâncias tóxicas do corpo, sejam elas parasitas, ou "matéria impura" (por exemplo, comida mestiça) ou dardos de doenças enviados pela pessoa que quer fazer mal. Mas, em todos os casos, utiliza-se uma metáfora que diz: "botar la suciedad" (despejar a sujeira), "botar la cochinada" (despejar a porcaria), "botar culo y boca" (despejar o cu e a boca), ou seja, livrar-se das impurezas do corpo para aumentar as forças e saúde geral.

Anteriormente foi mencionado que o equivalente mais típico da doença é o aparecimento de um inchaço, principalmente do abdômen, e que exigirá um tratamento de purificação imediata. Algumas dietas e purgas podem eliminar parasitas e impurezas decorrentes do excesso de alimentos e bebidas, mas a intervenção de um especialista é necessária quando há suspeita da existência de formas mais complexas de impurezas.

Este princípio de purificação e a prática de expurgos também ganharam aceitação entre os não-indígenas, especialmente em relação a parasitas de crianças. O leche (leite) de oje $e^{9}$ preparado pelos Quechua Lamas e Shuar/Achuar é muito procurado pelos nãoindígenas da região, apesar da grande disponibilidade de vermífugos nas farmácias. O uso principal da resina é o tratamento de parasitoses intestinais, mas também é usada por curandeiros amazônicos como um forte purgante para purificar o corpo de pacientes dos patógenos internos e também dos parasitas. Os não-indígenas geralmente presumem que as impurezas ingeridas que se alojaram no estômago pertencem à bruxaria, e que podem ser

\footnotetext{
${ }^{9}$ Da resina da árvore oje (Ficus insipida willd, também conhecida por Ficus anthelmintica).*
} 
desde uma bola de pena, ou um sapo pequeno, a embriões de cobras e semelhantes. E assim como os dardos da doença devem ser sugados, a "feitiçaria" deve ser vomitada.

Outra forma de depuração inclui o uso da fumaça de tabaco que se sopra sobre o corpo e a cabeça, e que geralmente é feito por um poderoso chefe da família ou, mais frequentemente, um xamã. Essa prática é comum entre os indígenas em todo o Alto Amazonas, e tem o objetivo de neutralizar a fraqueza causada pelo esforço físico, emocional ou mental. Isso também é usado com antecedência como profilaxia para experiências tensas, por exemplo, quando há uma festa na qual parentes e vizinhos provavelmente expressarão inveja de algo. Deve-se notar que pouca ênfase é colocada em parar a diarréia, o vômito e a reidratação. Portanto, se a lista de plantas purgativas impressiona, poucas são as mencionadas que possuem propriedades para curar a diarreia, demonstrando pouco interesse nos potenciais efeitos adversos daquela.

Para os povos indígenas, a noção de purificação é aplicada ao corpo todo e não sendo específica para nenhuma parte dele. Pelo contrário, os não-indígenas veem a purificação em termos de pureza de sangue. É amplamente aceito que pessoas com furúnculos têm "sangue sujo" e precisam ser purgadas - um conceito que também é encontrado nas culturas do sul da Europa. Portanto, estima-se frequentemente que o sangue é ou muito espesso, ou muito fino, e ambos casos requerem purga.

Os antiácidos disponíveis nas farmácias são amplamente aceitos por não-indígenas, e geralmente são usados sem a ajuda ou conselho de um médico, ou curandeiro. O Leite de Magnésio e o Sal de Andrews são muito populares como "auxiliares de purificação", ocasionalmente utilizados também pelos nativos.

\section{Uso de plantas medicinais e medicamentos}

Além de purificar e expurgar, existe um número considerável de fitoterápicos e remédios de farmácia que são utilizados em associação com a dieta, tanto por indígenas quanto por não-indígenas. Deve-se ressaltar que, exceto nos casos mais agudos, o atendimento é sempre buscado primeiro no grupo de parentesco ou entre especialistas de meio período. Existem diferenças consideráveis entre indígenas e não-indígenas na busca de tratamento dentro do grupo imediato ou entre amigos e parentes próximos, e isto é baseado tanto na perspectiva geral de saúde quanto nos papéis em função do gênero.

Geralmente, as mulheres indígenas são quem dão o primeiro passo quando implica o tratamento de bebês, crianças pequenas e para si mesmas. Para isso, elas usam ervas medicinais, que consistem quase exclusivamente de ervas selvagens ou cultivadas, algumas das quais são indígenas e outras introduzidas pelos espanhóis. Entre os Quechua Lamas, o conhecimento e o uso de plantas são marcantes, enquanto o tratamento com plantas tem um papel menor entre os Shuar/Achuar. Os remédios fitoterápicos são preparados com ingredientes frescos e são administrados imediatamente, na forma de infusões ou banhos, ou aplicados diretamente no corpo. 
Ocasionalmente, as mulheres tomam a iniciativa de realizar alguns rituais para neutralizar a feitiçaria, mas normalmente esta é uma atividade realizada pelos xamãs, desde que haja um disponível. Se o pai da criança ou o marido da mulher for um xamã, este, por sua vez, terá um papel importante nas decisões de tratamento. Particularmente, os remédios fitoterápicos também variam de acordo com as inclinações pessoais de cada xamã e, enquanto alguns são especialistas e conhecedores de plantas, outros preferem usar o ritual de purificação através do sopro.

Vale ressaltar que as mulheres indígenas possuem a habilidade de preparar remédios para elas e seus familiares. No entanto, caso residam em casas afastadas, e mesmo sabendo muito sobre as propriedades curativas das plantas, na presença ou proximidade de nãoindígenas, essas mulheres procuram imediatamente a ajuda de outras mulheres. Da mesma forma, quando os remédios da farmácia são populares, as mulheres Quechua Lamas e Shuar preferem obtê-los com suas comadres mestiças do que comprá-los nas farmácias locais, pois são geralmente administradas por estranhos, e isso acontece ainda quando as comadres vendem os remédios por um preço maior.

Isto explica, portanto, o motivo pelo qual a maioria das mulheres dos colonos tem em suas casas um suprimento de aspirina, um supressor de febre e analgésicos (aspirina, antalgina) para poder vendê-los aos nativos ou aos colonos vizinhos, se necessário. As mais reconhecidas são as comadres que sabem aplicar injeções, a forma de tratamento mais popular entre os indígenas e a maioria dos colonos do Alto Amazonas. As mães indígenas muitas vezes preferem essas mulheres que sabem administrar injeções, embora apenas uma ou duas mulheres mestiças em cada comunidade sejam especializadas nesta função. Contudo, as mulheres indígenas diferem claramente das mulheres mestiças por rejeitarem os gessos e ataduras, comumente usados pelas mulheres mestiças.

$\mathrm{O}$ exposto anteriormente cria uma crença específica. Pelo status que têm como mulheres brancas, as mulheres mestiças se julgam - e também são consideradas pelos indígenas - como conhecedoras dos segredos do cuidado da saúde, acreditando-se que gostam de ensinar aos indígenas como se cuidar, pois, a capacidade de cuidar de si mesmo é entendida como parte do processo de virar alguém "civilizado".

Outro ponto dessas relações que chama a atenção: quando os indígenas da região dos Quechua Lamas preparam em casa um banho ou preparo de ervas, uma criança é enviada para trazer comprimidos (geralmente analgésicos) de um vizinho ou uma comadre. Em caso de febre alta ou erupção cutânea, em vez disso, é enviado um curandeiro de meio período, que é a pessoa a quem a mulher mais velha da família consulta em casos de doença. Ele pode recomendar uma ou duas injeções, ou comprimidos de antibióticos. Durante os estágios iniciais do atendimento domiciliar, tratamentos caseiros com ervas ou remédios de farmácia, administrados por mulheres mestiças sem treinamento especial, são usados simultaneamente. Se o indivíduo não melhorar posteriormente, a atenção de um xamã será procurada, porém, o xamã pode se recusar a tratar o paciente por já ter usado esses remédios. 
Se o xamã aceitar tratar o indivíduo, o eventual fracasso da melhora do paciente poderia também ser atribuído ao uso que ele fez desses remédios. Porém, apesar da ameaça dos xamãs contra a combinação de tratamentos, não é raro que um indivíduo utilize medicamentos comprados em farmácia, ou os serviços de um xamã e serviços de saúde modernos em simultâneo para a mesma doença. Também pode surgir alguma ambiguidade nesse sentido, porque os conselhos sobre a conveniência ou não do uso de remédios alternativos, tanto fitoterápicos quanto os de farmácia, podem vir tanto de parentes indígenas ou de vizinhos não-indígenas. Essas alternativas serão então utilizadas se os remédios iniciais não tiverem proporcionado o resultado esperado, ou seja, a recuperação da saúde. Se também tiverem falhado as novas alternativas, o atendimento domiciliar é dado por terminado. Assim, o paciente irá consultar um xamã, possivelmente para realizar o ritual de "sugar"' a doença, ou poderá ser encaminhado ao posto de saúde para receber uma injeção, geralmente de antibióticos. O estágio de cuidado de casa para doenças agudas, por exemplo, um padecimento que causa febre, vômito, diarreia ou recusa em se alimentar, geralmente dura menos de um dia, e raramente mais de dois ou três dias.

No entanto, os tratamentos caseiros também são mais profundos. Em particular, se um indivíduo da família sofre de fraqueza geral, uma forma de tratá-lo seria soprar a fumaça de tabaco sobre sua cabeça e o corpo todo. Embora os xamãs que realizam rotineiramente essa purificação com tabaco no início das sessões de cura, os chefes de família que gozam da condição de "homens fortes" também podem realizar esse ritual em um parente, e ocasionalmente realizá-lo em uma visita. Isso se dá porque se pensa que quanto mais poderoso for o ritual do executor do medicamento, mais eficaz será a ação purificadora. Um indivíduo que foi purificado tem, então, o "corpo curado" ou o "corpo preparado" contra os possíveis agentes causadores da doença. Deve-se notar que a purificação com fumaça de tabaco é uma atividade privada, normalmente realizada no escuro e com as portas fechadas, ou em um local isolado na mata.

\section{Consulta com o xamã}

A decisão de consultar um xamã é finalmente tomada quando surgem suspeitas sobre a causa da doença. Isso pode ser feito bem no início do processo da doença, caso o paciente tenha, por exemplo, um sonho premonitório e claramente relacionado à moléstia. Contudo, também pode ser feito mais tarde, se a resposta ao tratamento não for a esperada. A decisão pode ser tomada por qualquer pessoa presente e que possua uma posição de autoridade. Por exemplo, se estiverem presentes apenas a mãe e a avó da criança, a decisão será tomada pela avó. No caso de que o marido e o sogro da mulher estiverem presentes, será a decisão do sogro. Quando houver a presença de vários homens adultos com a mesma condição de autoridade, o caso será discutido em conjunto, enquanto as mulheres permanecem afastadas, mas ocasionalmente dão sua opinião à distância.

Pode ser que haja um xamã disponível no grupo de parentesco. Nesse caso, haverá maior continuidade entre o atendimento de casa e a consulta com o xamã. Caso contrário, 
ocorre uma discussão especial entre os membros do grupo, uma vez que consultar um xamã fora do grupo de parentesco local ativará diferentes vínculos com ele e com seus parentes. Entre os Quechua Lamas indígenas, as decisões a respeito da consulta com o xamã parecem ser tomadas com base nos laços de afinidade ou consanguinidade do paciente com um determinado xamã. Entre os Shuar/Achuar, parece que a solidariedade grupal é maior e o "grupo de pacientes que administra a terapia" (JANZEN1978) determina qual é o xamã que deverá ser consultado. Em relação ao tratamento de doenças graves, os xamãs que não pertencem ao grupo de parentesco, mas são considerados como mais poderosos, podem ser os primeiros a serem consultados. Há casos em que os parentes dos xamãs são os primeiros a procurar atendimento médico ou a consultar outros xamãs. Isso pode ser comparado à decisão de um médico de enviar um membro da família a um colega.

Em contrapartida, as mulheres indígenas não têm reconhecimento ou prerrogativa especial de serem "curandeiras", ao contrário de outras mulheres que sim, o são. Por isso, controlam o cuidado de casa e neste caso os homens são muito pouco consultados, seja na eleição ou preparação de remédios, ou nas decisões tomadas em relação à terapia. A intervenção desses curandeiros é esperada apenas quando a busca por terapia se estende além dos xamãs ou dos médicos.

Entre os colonos, onde a interação entre as famílias das comunidades é constante, procuram-se conselhos sobre terapia entre parentes, companheiros e vizinhos, antes de se tomar a decisão de consultar um especialista, seja ele do setor formal ou informal.

\section{Tratamento de padecimentos específicos: acidentes, picadas de cobra e cuidados na gravidez e no parto}

Vamos ver, agora, o que acontece em relação a padecimentos específicos. Enquanto os não-indígenas costumam tratar certas condições nos postos de saúde, um número indeterminado de condições, como queimaduras, cortes, hematomas e entorses, são atendidas em casa pelos indígenas, desde que não haja suspeita de que sejam feitiços. Apenas o tratamento com ervas é usado para esses problemas, embora em muitos casos não haja nenhum tratamento específico.

Por sua vez, as fraturas graves são tratadas recorrendo a especialistas em ossos (hueseros), sejam indígenas (que não existem entre os Shuar/Achuar) ou não, também especializados em fitoterapia e quiropraxia. Esses hueseros às vezes são xamãs, às vezes não. Nas áreas Quechua Lamas e Shuar/Achuar há pouca disposição para aceitar qualquer tipo de curativo, principalmente gesso. A resistência ao gesso é generalizada entre os povos indígenas do Alto Amazonas e também é comum entre muitos membros da população mestiça. No caso das fraturas simples, o atendimento é feito nas casas, no caso dos indígenas Quechua Lamas, e nos Shuar/Achuar mais tradicionais é feito a partir de aplicações fitoterápicas. Em contraste, aqueles que possuem contato mais próximo com os colonos não estão mais familiarizados com esses procedimentos fitoterápicos e frequentemente procuram atendimento em outros lugares. 
Por outro lado, se tiverem algum tipo de acidente (principalmente quedas com fratura), que são muito comuns, as pessoas falam com prazer sobre o seu tratamento, realizado em conjunto com a dieta de "cura". Atualmente existem hueseros não-indígenas que utilizam uma combinação de fitoterápicos com manipulações manuais, e viraram populares, porque muitas pessoas tiveram experiências ruins com as placas de gesso aplicadas em diferentes postos de saúde ${ }^{10}$.

No caso de picadas de cobra, os cuidados são muitas vezes realizados em casa, ou seja, sem a ajuda de curandeiros ou especialistas nesse tipo de picada. Embora a maioria dos chefes de família esteja ciente de algum tratamento, certas pessoas em algumas aldeias ganharam a reputação de serem excepcionalmente habilidosas e se tornarem verdadeiras especialistas. Alguns outros afirmam ter a cura para picadas de diferentes cobras e integram em seus antídotos um número maior de componentes, especialmente o veneno contra elas ${ }^{11}$. Por esse motivo, apesar de que alguns postos de saúde estejam atualmente bem equipados com soro antiofídico, a maioria dos tratamentos para picadas de cobra ocorre no setor informal, com ou sem a intervenção do especialista local.

Os contrastes entre as culturas indígenas e não-indígenas e as formas tradicionais e modernas de assistência à saúde são mais marcantes quando se trata da assistência à maternidade. As crenças e práticas tradicionais sobre gravidez, parto e puerpério ainda são fortemente defendidas pelos indígenas do Alto Amazonas. No entanto, não existe o papel tradicional de "parteira" entre os indígenas. No caso dos não-indígenas, pelo contrário, as formas tradicionais de cuidado são generalizadas, e as parteiras desempenham um papel importante no cuidado informal. Quando ocorre o parto, geralmente o atendimento domiciliar é privilegiado, tanto entre indígenas quanto não-indígenas, e a maioria das mulheres declara que prefere parir em casa. A mulher indígena é atendida por um parente próximo ou por um especialista mestiço, pois, como já dissemos, não existe a figura de "parteira". Normalmente, a mulher indígena irá ao especialista da população mestiça apenas se tiver problemas durante o trabalho de parto, mas não acodem desde o início; diferentemente das mulheres não-indígenas que fazem arranjos com a parteira durante a gravidez.

\section{O comportamento de indígenas e colonos em comunidades mistas frente à doenças graves}

\footnotetext{
${ }^{10}$ Em Tarapoto (Perú), um huesero ficou famoso por tratar jogadores de futebol, que muitas vezes o procuram de grandes distâncias.

${ }^{11}$ Este é um domínio exclusivamente do homem. Poucos não-indígenas se tornam especialistas em cobras. A eficácia do tratamento oferecido pelos especialistas em cobras é um tema controverso, pois a eficácia terapêutica das preparações não foi comprovada. As genealogias Quechua Lamas, no entanto, mostram menos casos de mortes por picadas de cobra do que se poderia esperar, e muitos colonos afirmam que devem sua sobrevivência a especialistas indígenas em cobras. O tratamento da picada de cobra e o seu ritual de cura eficaz (festa da cobra) foram descritos por Wampash (1987).
} 
A seguir, oferecemos um estudo de caso da região Lamista, para ilustrar os complicados procedimentos existentes em relação à interpretação e ao tratamento de doenças graves e/ou de longa duração. Outros casos serão apresentados no Capítulo XII no contexto do pluralismo médico. (Em todos os estudos de caso, os nomes das pessoas foram alterados).

A busca da cura de um bebê com doença de "patco"

(Região dos Quechua Lamas)

Justiniano Salas, um homem idoso, era um respeitado chefe da família Lamista. Ele participou da formação de uma comunidade, originalmente indígena, que atualmente está se ampliando com a chegada de novos colonos não-indígenas. Sua família é formada por sua esposa, Celia, três filhos e quatro filhas. Um de seus filhos, e todas as mulheres, são casados. Seu filho casado vive na nova aldeia mista, enquanto três de suas filhas se casaram em uma comunidade indígena, longe da colonização. Por outro lado, contrariando as regras de residência pós-casamento, um genro de Justiniano mudou-se para sua casa e uma de suas filhas, Gregoria, permaneceu na casa dos pais quando o marido aceitou um emprego como trabalhador migrante na nova rodovia.

Gregoria, aquela cujo marido trabalha na rodovia, tinha um filho de seis meses que desenvolveu "patco". A língua do bebê então ficou branca, pequenos pontos vermelhos apareceram em seu rosto, e não conseguia se alimentar bem. Enquanto o bebê estava doente, Justiniano ficou afastado (algumas semanas); então, Celia, sua esposa e avó da criança, preparou uma infusão das ervas Lluichua Sacha (Caladium vents aracea) e Congona (Peperomia inaqualifolia), que coletou nos arredores da colônia.

Gregoria bebeu primeiro a decocção, que estava ligeiramente amarga. Quando o bebê mamava, chorava e não queria continuar mamando, e tinha febre. Enquanto isso, a irmã mais velha de Gregoria veio visitá-la com seus filhos e manifestou seu desejo de ajudá-la. Mais tarde, junto de Celia, partiram para a colheita de mais ervas aromáticas (Peperomia galoides). As folhas foram moídas em um pilão de madeira e adicionaram água para banhar o bebê nesta mistura. Nesse ínterim, Célia conversou com uma comadre mestiça, esposa de um comerciante de café que compra safras dos índios, e perguntou se o bebê poderia receber uma injeção. A mulher concordou em fazer a aplicação.

Nesse momento, o bebê já tinha uma febre um pouco mais alta, e por isso começaram a falar da possibilidade de que esse "patco" fosse devido ao "ayakuyashka", ou seja, uma doença transmitida por alguma alma. Essa possibilidade foi, contudo, eliminada por se pensar que se tratava de um ato de feitiçaria praticado contra o pai da criatura, e acreditava-se que poderia ter afetado a 
criança por não ter atingido o pai. O pai do bebê era um jovem ambicioso com aspirações no mundo branco e que se destacou no exército.

Embora trabalhasse como operário de construção na rodovia (estrada que fica às margens das matas), corria o boato de que estava aprendendo a dirigir grandes caminhões Volvo, ou já os havia dirigido, às vezes até Lima. Gregoria e suas irmãs falavam, portanto, de inveja e que seus efeitos eram a causa da doença do bebê. Finalmente, à tarde, o menino recebeu uma injeção de penicilina na casa da comadre, e estiveram presentes o bebê, Gregoria, a irmã com seu filho, Celia e um de seus filhos mais novos.

Na manhã seguinte foi preparado outro banho para o bebê. Seu estado não havia mudado muito. Ele ainda não conseguia mamar bem, foi alimentado com água fervida e banana amassada, na colher. Isso foi feito graças ao conselho da irmã mais velha, que aprendera esse tratamento de uma missionária protestante. Decidiu-se também dar leite de coco ao bebê e também a mãe tomou. A injeção, no entanto, não proporcionou muita melhora até aquele momento e decidiu-se praticar um ritual. Porém, o irmão de Justiniano, que era xamã e a quem era possível acudir, não estava lá naquela época, e o próprio Justiniano teve de ser consultado. Foi então enviado um de seus filhos mais novos para procurá-lo porque estava longe.

Contudo, à tarde, Celia soube que um comerciante de Lamas que abastecia a loja local, viria com seu caminhão. Embora Justiniano ainda não tivesse sido consultado, Celia saiu apressada e correu para a loja com Gregoria, o bebê e suas outras duas filhas. Seus filhos foram também logo depois. Todas juntas esperaram a tarde inteira pela chegada do caminhão. Quando chegou, Celia perguntou ao comerciante se ele poderia permitir que ela usasse um pouco de água do radiador e um pouco de gasolina do caminhão. $\mathrm{O}$ comerciante aceitou depois que o lojista, que olhava com simpatia para as crenças de seus clientes indígenas, explicou que Celia queria usar um pouco da água do caminhão, pois o bebê havia sido enfeitiçado porque seu pai dirigia um. O lojista conhecia as crenças relacionadas aos feitiços. Nesse ínterim, muita gente já havia se reunido, observando ao lojista colocar sua credibilidade na cura, em risco. Nesse momento, Celia tirou uma abóbora de seu lenço e misturou um pouco da água do radiador com gasolina. Depois, adicionou água fria à mistura quente, antes de derramar sobre o corpo do bebê, enquanto fazia que o bebê tocasse o caminhão várias vezes. Ao mesmo tempo, Gregoria, com um pano que o comerciante usava para limpar seu motor, esfregava o corpo do bebê, e Célia segurava o bebê e despejava a mistura no pano.

Posteriormente, o bebê foi enfaixado e levado para casa. Seu estado começou a melhorar lentamente nos dias seguintes, sendo a cura atribuída ao ritual do caminhão. A essa altura, Justiniano já havia retornado e à noite soprou 
fumaça de seu cachimbo no corpo do bebê. Debatiam se deviam ou não consultar um xamã, mas como o bebê estava melhorando, não foi mais considerado necessário. A culpa acabou sendo colocada em outros indígenas que trabalhavam com o pai da criança e que tinham inveja de sua habilidade para dirigir caminhões. Durante todo esse tempo, a mãe do bebê permaneceu bastante passiva e todas as decisões durante a ausência do pai do bebê foram tomadas por sua mãe.

Dessa forma, este estudo de caso ilustra as etapas típicas do tratamento de uma doença, os modos próprios de tratamento entre os Quechua Lamas e outros aspectos comuns característicos do processo de busca da cura, incluindo as decisões do grupo quanto à interpretação da causalidade; as mudanças nos conceitos etiológicos que levam a uma modificação nos tratamentos; o atendimento domiciliar, seguido do uso de medicamentos e injeções; o que implica o uso do sistema de compadrazgo ("compadrio") e; por fim, o tratamento posterior, realizado com base nos princípios da magia imitativa.

\section{A classificação das doenças no contexto interétnico}

No vínculo índio-colono, finalmente encontramos um elemento principal de explicação. A classificação das doenças indígenas tem sido afetada certamente pelo contato contínuo com os colonos e pelas epidemias que se seguiram aos períodos iniciais de contato no século XVII. Por esse motivo, os indígenas das matas geralmente fazem menção e distinção entre "nossas doenças" e as "doenças dos brancos", referindo-se principalmente às doenças infecciosas (pragas). Há também uma clara diferenciação entre aquelas doenças como as "nossas" (danos, feitiçaria) que são atribuídas à bruxaria, como uma categoria oposta à categoria das "doenças brancas", que se pensa serem contraídas por contágio. Na região Lamista, as doenças atribuídas à feitiçaria passam a ser designadas como "mal de la posta" (doença de posto), quer dizer, doenças que devem ser tratadas nos postos de saúde, ou que correspondem a pragas e varíola (epidemias).

Por tanto, a relação entre a classificação das doenças indígenas e dos colonos varia de acordo com o vínculo indígena-colono. Por exemplo, na área de fronteira Shuar/Achuar, há um claro contraste entre os esquemas de classificação de um e de outro. Oficialmente, os colonos dizem rejeitar a existência de bruxaria. $\mathrm{Na}$ área de fronteira Lamista, por outro lado, os colonos incorporaram o esquema de classificação indígena, buscando estabelecer correspondências entre as categorias hispânica e indígena, e, por sua vez, as categorias dos colonos foram introduzidas nos esquemas indígenas. Em todos os lugares e em vários graus, as ideias médicas modernas sobre a causalidade das doenças foram, então, sobrepostas aos esquemas de indígenas e colonos. Contudo, em vez de fornecer uma classificação alternativa, deram origem a novos nomes dentro de uma classificação cada vez mais sincrética.

Os exemplos apresentados mostram uma sobreposição considerável entre os nomes dos colonos e os dos povos indígenas. Isto demonstra que essa troca ocorre além das 
fronteiras étnicas e culturais, e que se reproduz mesmo quando os limites étnicos são muito rígidos, o que acontece tanto nas regiões Shuar/Achuar como Lamista. Além dos conceitos compartilhados como resultado da troca, também parece haver muitos conceitos, crenças e práticas que são semelhantes ou idênticos e cuja semelhança não é o resultado de um intercâmbio produzido além das fronteiras étnicas. Por exemplo, a oposição quente/frio pode ser originária entre os povos indígenas, ou pode ter sido transmitida através da cultura hispânica, como geralmente se supõe (BUTT-COLSON 1981).

Uma grande dificuldade que ocorre com qualquer tentativa de classificar ou comparar termos e conceitos de doenças entre grupos e fronteiras étnicas surge do fato de que, qualquer doença, independentemente de sua classificação original ou do pressuposto de sua etiologia, pode ser designada à categoria de síndromes ou sintomas do esquema de classificação. Daí vem nossa crítica às distinções frequentemente feitas pelos antropólogos médicos entre doenças naturais e sobrenaturais (STAIANO 1986).

A causalidade natural mais frequentemente assumida é dada em áreas onde as fronteiras étnicas são fracas, uma vez que as noções de bruxaria são fortes quando se tratam de áreas com um componente importante de identidade indígena ou em áreas indígenas isoladas (Lamista, Napo Quechua, Shuar/Achuar, Aguaruna). Em locais urbanos com grande densidade populacional, porém, a feitiçaria também é considerada sem reservas como a principal causa de adoecimento e morte entre os descendentes mestiços de indígenas e colonos. Da mesma forma, a maioria da população de colonos, seja ela rural ou urbana, tem a crença de que as doenças são causadas pela feitiçaria.

\section{Referências Bibliográficas}

BUTT COLSON, Audrey. (1981). An amerindian derivation for Latin American Creole illness and their treatment. Social Science Medicine, vol.17, p.1229-1248.

JANZEN, John M. (1978). The quest for therapy in lower Zaire. Los Angeles: Univ. of California Press, Berkeley.

KROEGER, Axel; BARBIRA-FREEDMAN, Françoise. (1992). Salud y enfermedad en el alto Amazonas. In: "La lucha por la salud en el alto amazonas y en los andes", Alemanha/Cambridge: Ed. Abya Yala.

STAIANO-ROSS, Kathryn. (1986). Interpreting signs of illness. A case study in medical semiotics. Monton de Gruyter, Berlin, New York, Amsterdam.

WAMPASH, Manuel. (1987). La celebración de la culebra. INBISH (Bomboiza).

sobre os autores

\section{Axek Kroeger}

Professor de Saúde Comunitária Internacional na Escola de Medicina Tropical da Universidade de Liverpool e do Centro Médico Universitário da Universidade de Freiburg. 


\section{Françoise Barbira-Freedman}

Afiliated lecture do Departamento de Antropologia da Universidade de Cambridge. Também é fundadora da organização Birthlight Trust.

sobre as tradutoras

\section{Aline Regitano}

Doutoranda em Antropologia Social pela Universidade de São Paulo, com mestrado em Antropologia pela Universidade de Campinas.

\section{Anaí Vera Britos}

Doutoranda no Programa de Pós-Graduação em Antropologia Social da Universidade de São Paulo. Mestra em Antropologia Social pelo Programa de Pós-Graduação em Antropologia Social da Universidade Federal de Santa Catarina.

Recebido em 12/09/2020

Aceito para publicação em 30/12/2020 